\title{
Variations in Adsorption of Two Step Solvent Extracted Vitrain and Their Coal Crystallites Response
}

\author{
Run CHEN, Youyang WANG, Zhiyang WANG
}

\begin{abstract}
Adsorption capacity and crystallite characteristics of raw vitrains collected from western Guizhou and eastern Yunnan and their step extracted residues were analysed; the possible geochemical mechanism of methane adsorption on coal crystallite was discussed. The results show that the step extraction changes methane adsorption capacity on sample, and the change direction and magnitude depend on the coalification degree. The extraction also depolymerizes the coal crystallite. It is found that it has a synchronous relationship between the percent change of adsorption and the percent depolymerization of coal crystallite. It is suggested that the second coalification jump plays a key role on the percent change of methane adsorption and the percent depolymerization of crystallite. The crystallite depolymerization is an important reason that methane adsorption percent changes.
\end{abstract}

Keywords: adsorption capacity; coal crystallite; organic solvent; stepwise-extraction; vitrain

\section{INTRODUCTION}

Coalbed methane $(\mathrm{CBM})$ is sourced from the organic matter through biogenic and/or thermogenic processes and stored in coal seams with absorbed state, in comparison to the reservoirs of the conventional nature gas. The reservoirs of the coal seams have low permeability and high porosity, which make CBM adsorption and desorption on coal become a key issue in coalbed methane geology research $[1,2]$.

To date, plenty of researches have been carried out in gases adsorption on coal to serve CBM exploration \& development or outburst of gas in coal mine. Methane adsorption capacity in coal is controlled by coal rank, maceral composition (maceral and ash content) and moisture content [3-9]. Coal rank appears to be the most significant control on methane adsorption capacity to the point that it complicates the relationship between methane adsorption capacity and maceral composition. There is a positive relationship between methane adsorption capacity and rank. There appears to be a negative relationship between methane adsorption capacity and ash content [10], implying that ash content is not an important control factor of methane adsorption capacity. Published data show bright coal has higher gas adsorption capacity than dull coal because of more micro pores with high surface areas in vitrinite than inertinite [11]. Low bituminous extracted residue has stronger methane adsorption than that of the raw coal because of the higher surface area [12]. Microporosity of vitrinite increases with coal rank, which is the reason that methane adsorption capacity increases with the rank [6,7]. Moisture content of a coal has shown to have a negative impact on methane adsorption capacity of coal [13-15].

However, the relationship between gas adsorption and coal crystallite has not been well investigated. In order to find the coal crystallite change impact on methane adsorption capacity, two step solvent extraction, methane isothermal adsorption and $\mathrm{X}$ ray diffraction techniques were applied.

\section{SAMPLES AND EXPERIMENTS}

Coal samples were collected from the Permian of western Guizhou and eastern Yunnan (Figure 1). All samples were collected from the native structure belt, and the coal rank is among low to high bituminous coal (Tab. 1). In order to eliminate the influences of the sediments and parent materials, vitrinites were separated and collected by hand firstly, and then pulverized to $<35$ mesh to enrich vitrinites using heavy liquid flotation method until the vitrinite content above $85 \%$ (Tab. 1).

Table 1 Maceral and mineral of vitrain

\begin{tabular}{|c|c|c|c|c|c|}
\hline \multirow{2}{*}{ Sample } & $R_{\mathrm{o}, \max }$ & \multicolumn{5}{|c|}{ Maceral and mineral (\%) } \\
\cline { 3 - 6 } & $(\%)$ & vitrinites & exinites & inertinites & minerals \\
\hline Haitian & 0.73 & 95.54 & 0.97 & 2.91 & 0.58 \\
\hline Tucheng & 1.04 & 87.42 & 3.56 & 8.54 & 0.48 \\
\hline Yuni & 1.28 & 85.77 & 0.38 & 11.39 & 2.47 \\
\hline Lingyuan & 1.53 & 89.67 & 0.19 & 9.37 & 0.76 \\
\hline Jinjia & 2.06 & 93.95 & - & 5.68 & 0.38 \\
\hline
\end{tabular}

Solvent extraction experiments were carried out in Soxhlet extractor under sonic oscillation condition at room temperature; $\mathrm{CS}_{2}$ was used as the first step extraction solvent, and then benzene was used as the second step extraction solvent for the first extracted residue.

The high pressure isothermal adsorption tests were carried out using a Laboratory Isotherm Adsorption System (Mode: IS-100, TerraTek Inc, USA) at $30^{\circ} \mathrm{C}$, and each test included 6 different pressures. Approximately 80 $\mathrm{g}$ of each sample was dried for the adsorption test.

The samples for XRD (about $5 \mathrm{~g}$ ) were crushed and sieved to obtain particles of $<200$ mesh in diameter and then dried in a desiccator at $80{ }^{\circ} \mathrm{C}$ for $12 \mathrm{~h}$. All samples were demineralized to avoid the interference of mineral matter in coal before subjecting them to X-ray diffraction (XRD). An aliquot of homogeneous sample (about $1 \mathrm{~g}$ ) was weighed into a Teflon beaker and first digested by 10 $\mathrm{mL}$ of $\mathrm{HCl}$ three times (10 wt \%). Following each digestion, the solution was evaporated on a hot plate (about $60{ }^{\circ} \mathrm{C}$ ) until a final volume of $1-3 \mathrm{~mL}$. Then, distilled water was added to rinse the sample, and the supernatant was removed after 10-30 min of precipitation. Then the rinsed sample was mixed with $10 \mathrm{~mL}$ of 
concentrated HF $(50 \mathrm{wt} \%)$ to remove silicate minerals. The resulting solution was concentrated by distilling $(\sim 60$ ${ }^{\circ} \mathrm{C}$ ) to reach a final volume of $1-3 \mathrm{~mL}$, and $5 \mathrm{~mL}$ of concentrated $\mathrm{HCl}$ and $5 \mathrm{~mL}$ of concentrated $\mathrm{HF}$ were added and evaporated to dryness. Finally, the digested solution was boiled 2 times with distilled water. The demineralized coal was dried in an oven $\left(80^{\circ} \mathrm{C}\right)$.

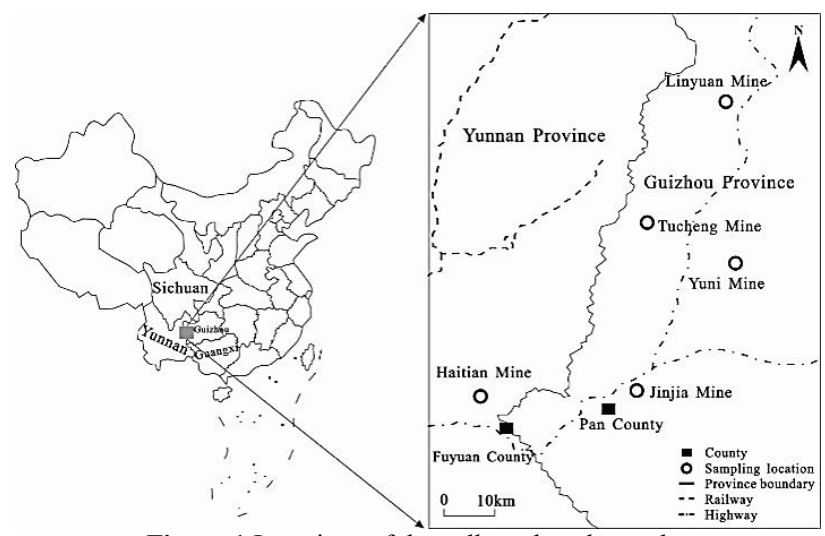

Figure 1 Locations of the collected coal samples

\section{RESULTS AND DISCUSSIONS}

\subsection{Adsorption Capacity of Raw and Extracted Vitrains}

Many studies about gases adsorption on coals have been carried out and several models have been conducted to characterize the adsorption and desorption behaviours, such as the Langmuir equation [16], BET model [17], DA and DR models [18].

In this study, the Langmuir equation is used to describe the adsorption equilibrium of samples:

$V=\frac{V_{\mathrm{L}} p}{P_{\mathrm{L}}+p}$

where: $V$ is the volume of methane adsorption at equilibrium conditions $\left(\mathrm{cm}^{3} / \mathrm{g}\right), p$ is the system methane pressure $(\mathrm{MPa}), V_{\mathrm{L}}$ is the Langmuir volume at standard state with a pressure of $101 \mathrm{kPa}$ and the temperature of $273.15 \mathrm{~K}\left(\mathrm{~cm}^{3} / \mathrm{g}\right)$, and $P_{\mathrm{L}}$ is the Langmuir pressure (MPa).

Methane adsorption isotherms of the raw vitrains and their solvent step extracted residues are shown in Figure 2, and the Langmuir constants are given in Tab. 2 .

Fig. 2a shows that the volume of methane adsorption on Haitian vitrain extracted residues is larger than that of the raw vitrain at the same pressure, and the volume of methane adsorption on the second step extracted residue is the largest at the same pressure. It indicates that solvent step extraction increased methane adsorption capacity on Haitian vitrain, and the adsorption capacity increased with extraction step on Haitian vitrain.

Table 2 The Langmuir constants of raw vitrains and their extracted residues

\begin{tabular}{|c|c|c|c|c|c|c|}
\hline \multirow{2}{*}{ Sample } & \multicolumn{2}{|c|}{ Raw coal } & \multicolumn{2}{c|}{ First step extracted residue } & \multicolumn{2}{c|}{ Second extracted residue } \\
\cline { 2 - 7 } & $V_{\mathrm{L}}\left(\mathrm{cm}^{3} / \mathrm{g}\right)$ & $P_{\mathrm{L}}(\mathrm{MPa})$ & $V_{\mathrm{L}}\left(\mathrm{cm}^{3} / \mathrm{g}\right)$ & $P_{\mathrm{L}}(\mathrm{MPa})$ & $V_{\mathrm{L}}\left(\mathrm{cm}^{3} / \mathrm{g}\right)$ & $P_{\mathrm{L}}(\mathrm{MPa})$ \\
\hline Haitian & 14.99 & 5.19 & 21.8 & 5.52 & 17.89 & 5.35 \\
\hline Tucheng & 22.12 & 4.26 & 24.05 & 3.53 & 18.69 & 3.93 \\
\hline Yuni & 25.86 & 2.77 & 25.23 & 2.75 & 17.91 & 2.20 \\
\hline Lingyuan & 27.46 & 2.60 & 27.33 & 2.83 & 25.52 & 3.06 \\
\hline Jinjia & 28.87 & 3.00 & 27.89 & 2.82 & 21.79 & 3.29 \\
\hline
\end{tabular}

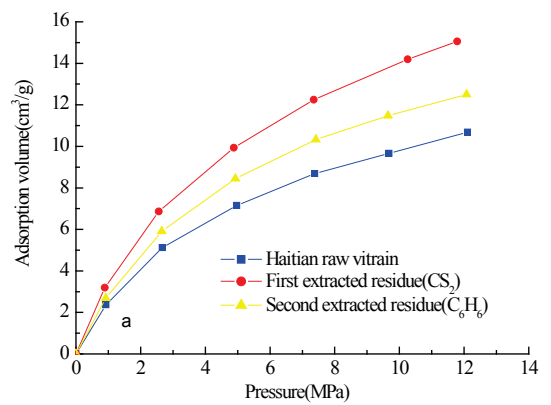

(a) Haitian coal

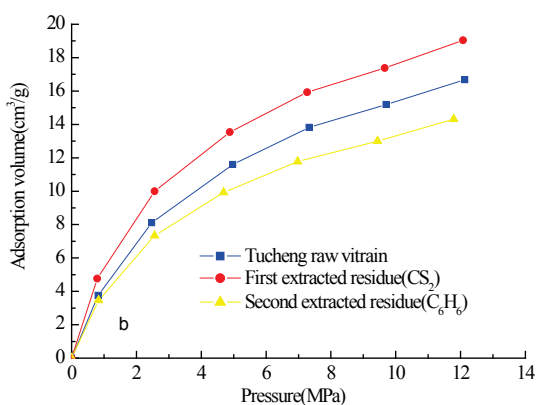

(b) Tucheng coal

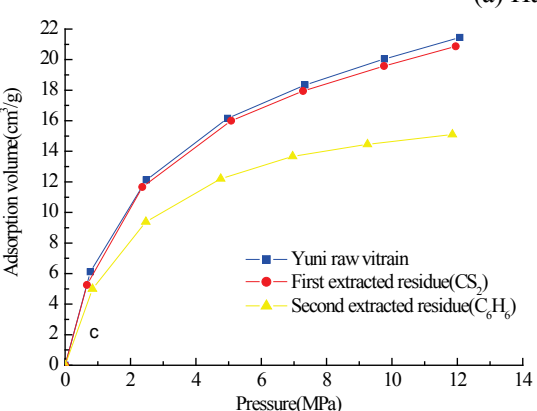

(c) Linyuan coal

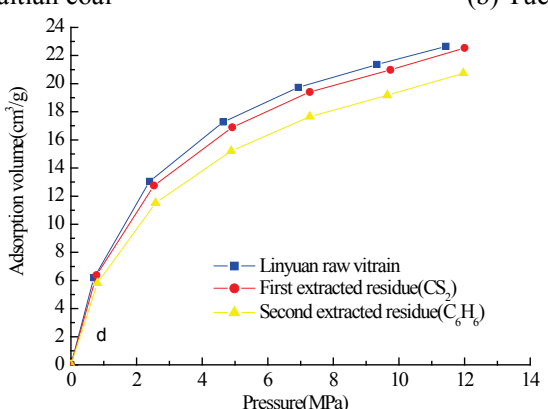

(d) Yuni coal

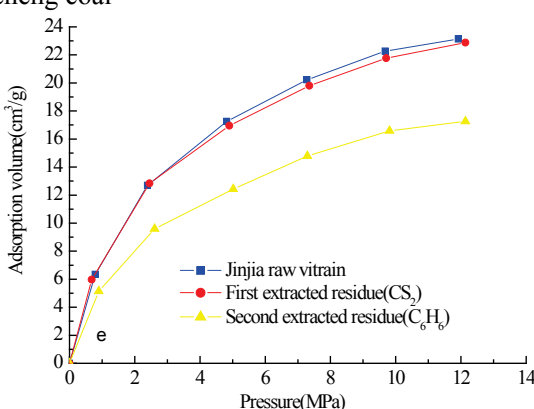

(e) Jinjia coal

Figure 2 Adsorption isotherms of the raw and its extracted vitrains

The volumes of the first and the second step extracted residues of Tucheng vitrain adsorbed methane are larger and lesser than that of the raw vitrain at the same pressure, respectively (Fig. 2b). It indicates that methane adsorption capacities on the first extracted residue and the 
second extracted are higher and lesser than those of the raw vitrain.

The volumes of the entire of the first and the second step extracted residues of other vitrains adsorbed methane are lesser than those of their raw vitrains, and the volume of methane adsorption on the second step extracted residue is the least at the same pressure condition (Fig. 2c $-2 \mathrm{e})$.

In order to further investigate the evolution of the percent change of methane adsorption capacity on vitrain step extracted residue to coal rank, $P_{V_{1}}$ and $P_{P_{\mathrm{i}}}$ are defined by the following equations:

$$
\begin{aligned}
& P_{V \mathrm{i}}=\frac{\left(V_{\mathrm{Li}}-V_{\mathrm{Lr}}\right)}{V_{\mathrm{Lr}}} \times 100 \% \\
& P_{P \mathrm{i}}=\frac{\left(P_{\mathrm{Li}}-P_{\mathrm{Lr}}\right)}{P_{L \mathrm{r}}} \times 100 \%
\end{aligned}
$$

where: $P_{V_{1}}$ is the percent change of $V_{\mathrm{L}}$ of the i step vitrain extracted residue $(\%), V_{\mathrm{Li}}$ and $V_{\mathrm{Lr}}$ is the $V_{\mathrm{L}}$ of methane adsorption on the $\mathrm{i}$ step extracted residue and the raw vitrain $\left(\mathrm{cm}^{3} / \mathrm{g}\right)$, respectively; $P_{P_{\mathrm{i}}}$ is the percent change of $P_{\mathrm{L}}$ of the i step vitrain extracted residue $(\%), P_{\mathrm{Li}}$ and $P_{\mathrm{Lr}}$ is the $P_{\mathrm{L}}$ of methane adsorption on the i step extracted residue and the raw vitrain $(\mathrm{MPa})$, respectively.
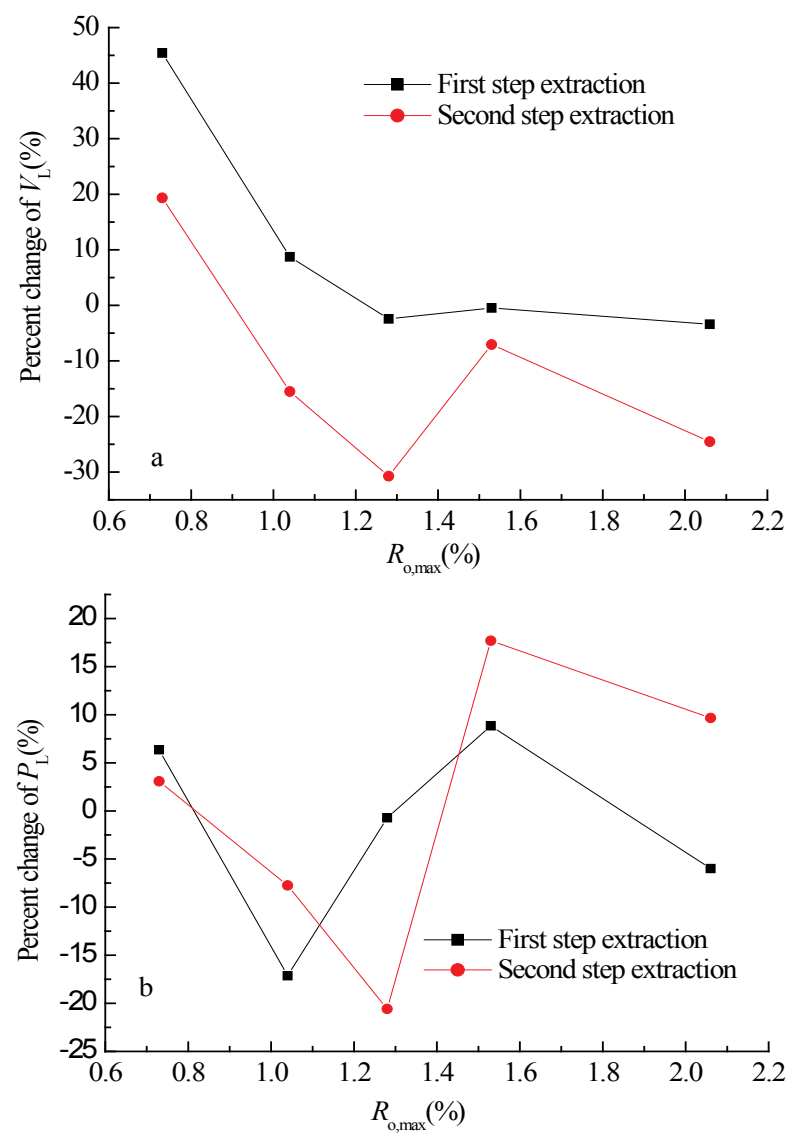

Figure 3 Plots of the percent change of Langmuir constants to coal rank

Fig. 3 shows that the $V_{\mathrm{L}}$ percent changes of the first step extracted residues are positive and negative before and after the second coalifiaction jump $\left(R_{0, \max }=1.3 \%\right)$, respectively. The $V_{\mathrm{L}}$ percent changes of the second step extracted residues are negative except that of Haitian vitrain residue. The $P_{\mathrm{L}}$ percent changes of two step extracted residues to coal rank have no obvious regularity. It is clear that methane adsorption capacity on vitrain extracted residues not only depends on the extractions of organic solvents, but is also controlled by the coalification degree.

\subsection{Crystallite of raw coal and extracted residue}

The structural parameters of coal crystallite, including the space between aromatic layers $\left(d_{002}\right)$, the lateral size $\left(L_{\mathrm{a}}\right)$, the stacking height $\left(L_{\mathrm{c}}\right)$ and the stacking layer $(N)$, are determined using the conventional Scherrer equations:

$$
\begin{aligned}
& d_{002}=\frac{\lambda}{2 \sin \theta_{002}} \\
& L_{\mathrm{a}}=\frac{1.84 \lambda}{B_{10 l} \cos \theta_{10 l}} \\
& L_{\mathrm{c}}=\frac{0.89 \lambda}{B_{002} \cos \theta_{002}} \\
& N=\frac{L_{\mathrm{c}}}{d_{002}}+1
\end{aligned}
$$

where, $\lambda$ is the wavelength of the radiation used, $B_{10 l}$ and $B_{002}$ are the full width at half-maximum of the $(10 l)$ and (002) peaks, and $\theta_{002}$ and $\theta_{10 l}$ are the corresponding scattering angles or peak positions. The crystallites of raw vitrains and their extracted residues are shown in Tab. 3 .

To study the percent change of the coal crystallite by solvent extractions, $P_{d 002 \mathrm{i}}, P_{\mathrm{Lai}}, P_{\mathrm{Lci}}$ and $P_{\mathrm{Ni}}$ are defined by the following equations:

$$
\begin{aligned}
& P_{d_{002 \mathrm{i}}}=\frac{\left(d_{002 \mathrm{i}}-d_{002 \mathrm{r}}\right)}{d_{002 \mathrm{r}}} \times 100 \% \\
& P_{L_{\mathrm{ai}}}=\frac{\left(L_{\mathrm{ai}}-L_{\mathrm{ar}}\right)}{L_{\mathrm{ar}}} \times 100 \% \\
& P_{L_{\mathrm{ci}}}=\frac{\left(L_{\mathrm{ci}}-L_{\mathrm{cr}}\right)}{L_{\mathrm{cr}}} \times 100 \% \\
& P_{N \mathrm{i}}=\frac{\left(N_{\mathrm{i}}-N_{\mathrm{r}}\right)}{N_{\mathrm{r}}} \times 100 \%
\end{aligned}
$$

where, $P_{d 002 \mathrm{i}}$ is the percent change of $d_{002}$ of the i step vitrain extracted residue $(\%), d_{002 \mathrm{i}}$ and $d_{002 \mathrm{r}}$ is the $d_{002}$ of the i step extracted residue and the raw vitrain $(\mathrm{nm}) ; P_{\text {Lai }}$ is the percent change of $L_{\mathrm{a}}$ of the i step vitrain extracted residue $(\%), L_{\mathrm{ai}}$ and $L_{\mathrm{ar}}$ is the $L_{\mathrm{a}}$ of the i step extracted residue and the raw vitrain $(\mathrm{nm})$, respectively; $P_{\mathrm{Lci}}$ is the percent change of $L_{\mathrm{c}}$ of the i step vitrain extracted residue $(\%), L_{\mathrm{ci}}$ and $L_{\mathrm{cr}}$ is the $L_{\mathrm{c}}$ of the i step extracted residue and the raw vitrain $(\mathrm{nm})$, respectively; $P_{\mathrm{Ni}}$ is the percent change of $N$ of the i step vitrain extracted residue $(\%), N_{\mathrm{i}}$ and $N_{\mathrm{r}}$ is the $N$ of the i step extracted residue and the raw vitrain, respectively. 


\begin{tabular}{|c|c|c|c|c|c|c|c|c|c|c|c|c|}
\hline \multirow{2}{*}{ Sample } & \multicolumn{4}{|c|}{ Raw coal } & \multicolumn{4}{|c|}{ First step extracted residue } & \multicolumn{4}{|c|}{ Second extracted residue } \\
\hline & $d_{002}(\mathrm{~nm})$ & $L_{\mathrm{c}}(\mathrm{nm})$ & $L_{\mathrm{a}}(\mathrm{nm})$ & $N$ & $d_{002}(\mathrm{~nm})$ & $L_{\mathrm{c}}(\mathrm{nm})$ & $L_{\mathrm{a}}(\mathrm{nm})$ & $N$ & $d_{002}(\mathrm{~nm})$ & $L_{\mathrm{c}}(\mathrm{nm})$ & $L_{\mathrm{a}}(\mathrm{nm})$ & $N$ \\
\hline Haitian & 0.3842 & 1.0342 & 2.0371 & 3.6170 & 0.3851 & 1.0282 & 2.0325 & 3.6620 & 0.3863 & 1.0275 & 2.0304 & 3.6410 \\
\hline Tucheng & 0.3531 & 1.4659 & 2.0457 & 5.0480 & 0.3548 & 1.451 & 2.0438 & 4.9950 & 0.3561 & 1.4483 & 2.0409 & 5.0450 \\
\hline Yuni & 0.3518 & 1.6439 & 2.2137 & 5.6320 & 0.3537 & 1.6266 & 2.2110 & 5.5660 & 0.3549 & 1.6218 & 2.2085 & 5.5710 \\
\hline Lingyuan & 0.3475 & 1.7683 & 2.1483 & 6.0410 & 0.3489 & 1.7525 & 2.1452 & 5.9850 & 0.3501 & 1.7506 & 2.1404 & 5.9120 \\
\hline Jinjia & 0.3443 & 2.0092 & 2.1742 & 6.8220 & 0.3451 & 1.9981 & 2.1675 & 6.7530 & 0.3459 & 1.9967 & 2.1596 & 6.6570 \\
\hline
\end{tabular}

The results show that the crystallites of vitrain extracted residues have significant change after the extractions. Compared to the raw vitrains, the spaces between aromatic layers $\left(d_{002}\right)$ of vitrain extracted residues are increased, and the largest increase magnitude is about $0.8 \%$ after the second step extraction (Fig. 4a). The stacking height and the lateral size of vitrain extracted residues are reduced, and the largest reduced magnitude after the second step extraction is about $-1.4 \%$

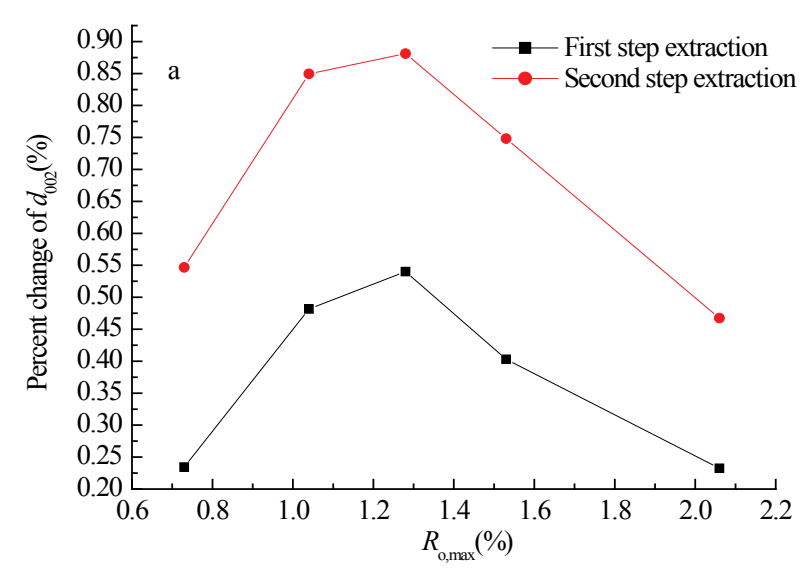

(a)

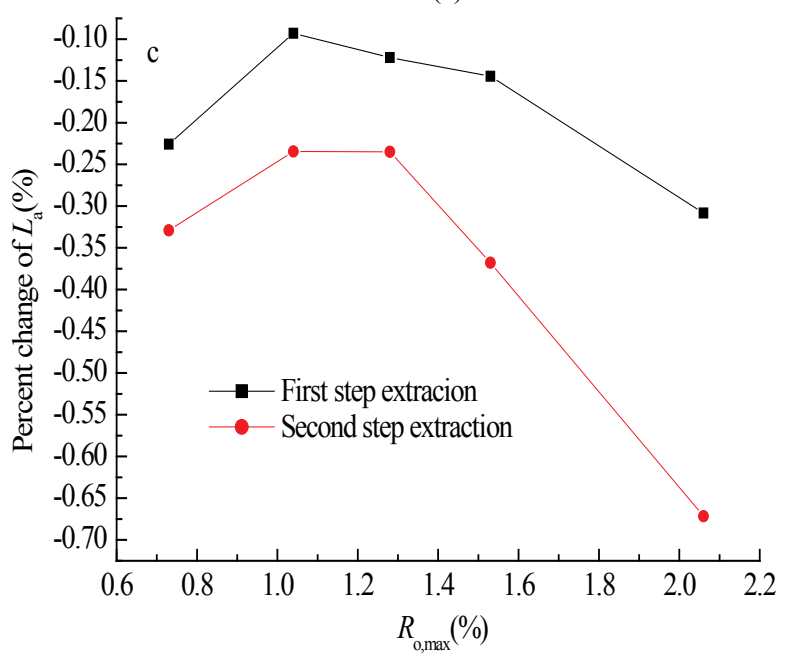

(c)

Figure 4 Plots of the percent change of coal crystallite to coal rank and $-0.7 \%$, respectively (Fig. $4 \mathrm{~b}-4 \mathrm{c}$ ). The percent change of the sticking layers of vitrain extracted residues is between $1.2 \%$ to $-2.4 \%$, and no obvious rule (Fig. $4 \mathrm{~d}$ ). The percent changes of structural parameters of crystallites indicate that the crystallites of vitrain are depolymerized by the first step extraction $\mathrm{CS}_{2}$ ) and the depolymerization of crystallites is aggravated by the second step extraction (benzene).

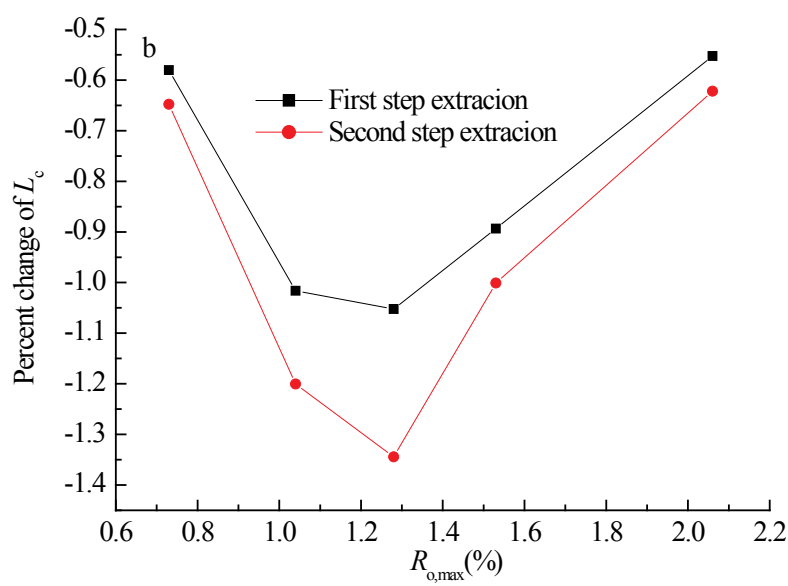

(b)

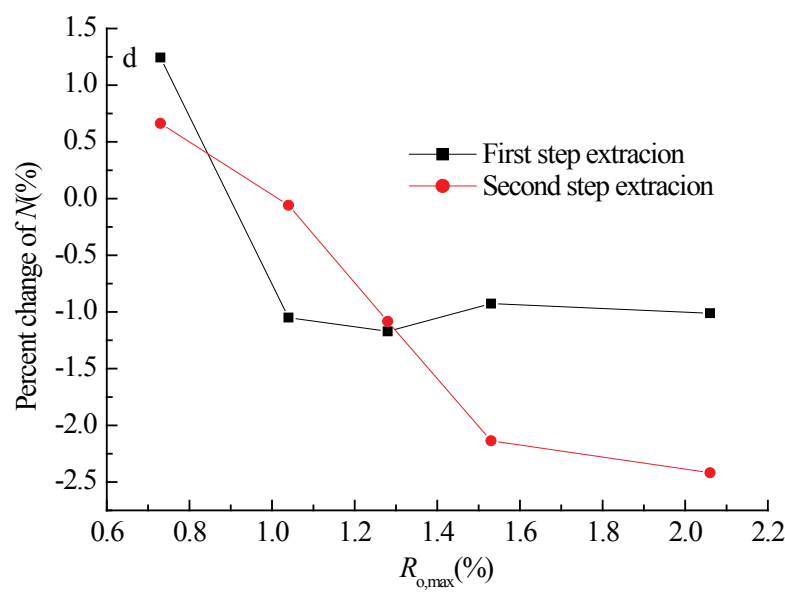

(d)
With the coal rank increasing, the percent change of $d_{002}$ and $L_{\mathrm{c}}$ increases, and the percent change of $L_{\mathrm{a}}$ reduces before the second coalification jump; and the percent change of $d_{002}$ and $L_{\mathrm{c}}$ decreases, the percent change of $L_{\mathrm{a}}$ increases after the second coalification jump. It means that the depolymeterizations of the crystallites of vitrain extracted residues were controlled by the coalification degree and the extraction step.

\subsection{Relationship between Adsorption Capacity and Coal Crystallite}

Compared the $V_{\mathrm{L}}$ percent changes with the percent changes of the crystallites by solvent extractions; it appears a synchronous relation. With the percent change of $d_{002}$ increasing, the percent change of $V_{\mathrm{L}}$ of extracted vitrain residue decreases (Fig. 5a). With the percent change of $L_{\mathrm{c}}, L_{\mathrm{a}}$ and $N$ increasing, the percent change of $V_{\mathrm{L}}$ of extracted vitrain residue increases (Fig. $5 \mathrm{~b}-5 \mathrm{~d}$ ). The results indicate that organic solvent extractions 
depolymerize coal crystallites to weak methane adsorption capacity on extracted vitrain residues.

In this study, we also noticed that a positive relationship appears between the percent change of $V_{\mathrm{L}}$ and the percent change of the crystallites of partial vitrain extracted residues before the second coalification jump. It is contrary to the negative correlation between adsorption capacity change and coal crystallite depolymerization. We think it may be because the soluble organic matter composition and functional groups change during the process of coalification. Published studies show that the reaction of the crack of oxygen-containing functional group is main form at the early stage. With coal rank increasing, the reaction turns to aromatics branched chain cracking, then to bituminous larger molecules crack during the stage of the coal-generated hydrocarbon process [19-23].

The transformation of the chemical reaction shows that the functional groups of coal are different during the coal-generated hydrocarbon process before and after the second coalification jump. At the same time, an investigation has shown that the carboxyl is the optimum space for methane adsorption in coal, and hydrocarbon molecules, with the functional groups of methyl and/or methylene, competitive adsorbed on coal crystallites with methane [24, 25]. Based on those, the changes of methane isothermal adsorption and coal crystallites may be influenced by the organic material composition and the functional groups of coal under the control of coalification degree before the second coalification jump is conducted, which is worthy of further investigation.

\section{CONCLUSION}

The step extractions of $\mathrm{CS}_{2}$ and benzene change the Langmuir constants of 5 vitrains, and the change direction and magnitude of Langmuir constants depend on the coalification degree. $\mathrm{CS}_{2}$ extraction enhances and reduces methane adsorption capacity on vitrain extracted residue before and after the second coalification jump, respectively. Benzene extraction reduces methane adsorption capacity on vitrain extracted residue except for Haitian vitrain extracted residues.
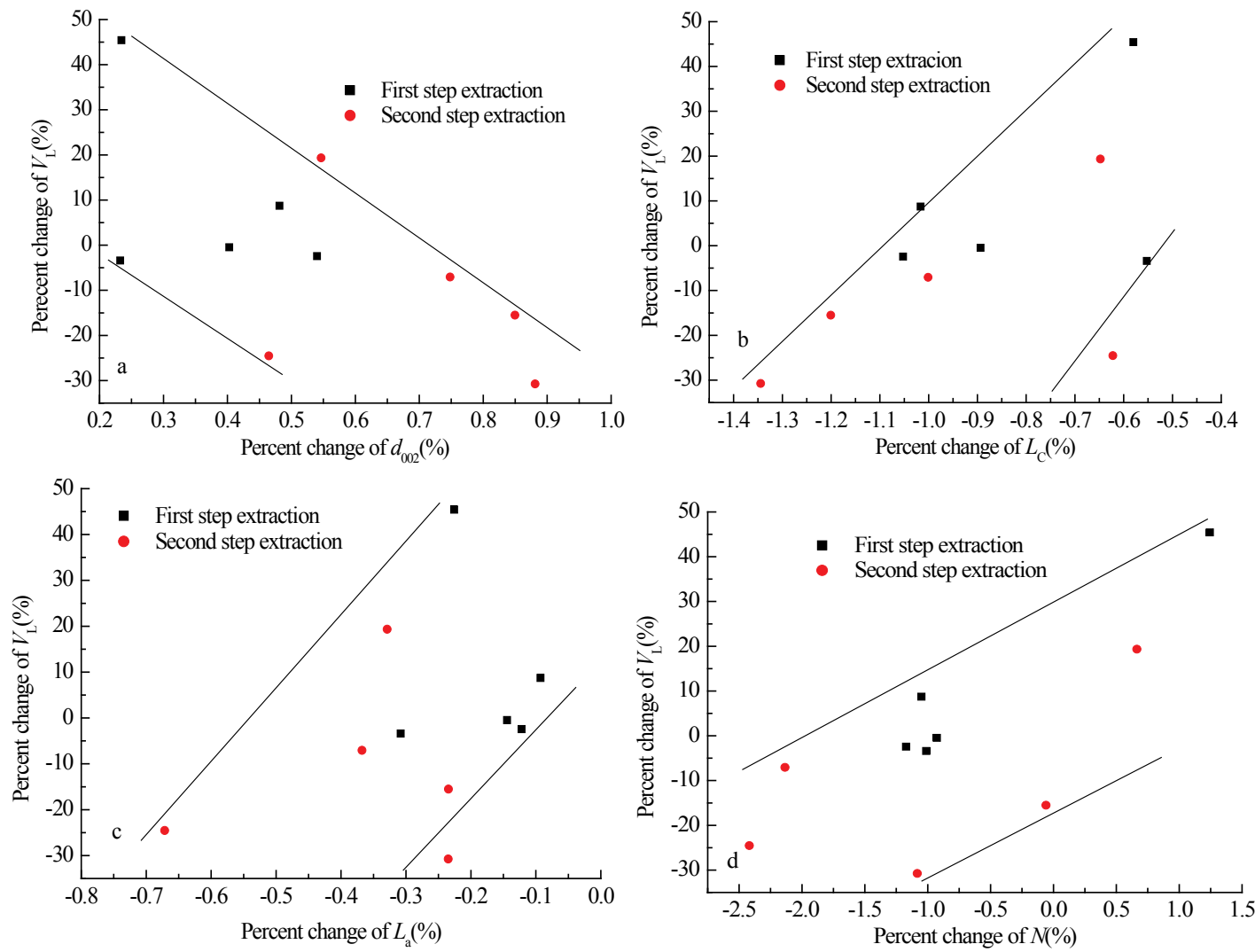

Figure 5 Plots of the percent change of $V_{\mathrm{L}}$ to the percent change of crystallite

The step extractions of $\mathrm{CS}_{2}$ and benzene make coal crystallite depolymerized. The depolymerisation of vitrain crystallite to coal rank increases and decreases before and after the second coalification jump, respectively. It indicates that the depolymerization of vitrain residue also depends on the coalification degree.

The second coalification jump plays a key role in the percent changes of methane isothermal adsorption capacity and the coal crystallite. A synchronous response appears between the percent change of adsorption capacity and the depolymerization of vitrainl crystallite.
Vitrain crystallite depolymerization by solvent extraction is the important reason why the volume of methane adsorption capacity on vitrain extracted residue reduces.

The percent changes of methane adsorption capacity and vitrain crystallite are in positive correlation in a few vitrain extracted residues before the second coalification jump, which may be influenced by the organic material composition and the functional groups of coal under the control of coalification degree before the second coalification jump, which is worthy of further investigation. 


\section{Acknowledgements}

This study is supported by the National Natural Science Foundation of China (No. 41572138) and The research fund of Henan Key Laboratory for Green and Efficient Mining \& Comprehensive Utilization of Mineral Resources (Henan Polytechnic University) (grant No. S201608).

\section{REFERENCES}

[1] Pophare, A. M. P., Mendhe, V. A., \& Varade, A. (2008). Evaluation of coal bed methane potential of coal seams of Sawang Colliery, Jharkhand, India. Journal Earth System of Science, 117(2), 121-132. https://doi.org/10.1007/s12040-008-0003-4

[2] Qin, Y. (2003). Several scientific problems faced in exploration and development of China's coalbed methane. Exploration and development of China's coalbed methane, Xuzhou, 14-20.

[3] Bustin, R. M. \& Clarkson, C. R. (1998). Geological controls on coalbed methane reservoir capacity and gas content. International Journal of Coal Geology, 38(1-2), 326. https://doi.org/10.1016/S0166-5162(98)00030-5

[4] Garnier, C., Finqueneisel, G., Zimny, T., Pokryszka, Z., Lafortune, S., Defossez, P. D. C., \& Gaucher, E. C. (2011). Selection of coals of different maturities for $\mathrm{CO}_{2}$ storage by modelling of $\mathrm{CH}_{4}$ and $\mathrm{CO}_{2}$ adsorption isotherms. International Journal of Coal Geology, 87(2), 80-86. https://doi.org/10.1016/j.coal.2011.05.001

[5] Fu, X. H., Xing, X., Liu, A. H., Fan, B., \& Zhou, R. (2011). Analysis of porosity, adsorption characteristics and well test results of coalbeds with different ranks in North China. Natural Gas Industry, 31(12), 72-75. https://doi.org/10.1016/S1003-9953(10)60155-7

[6] Laxminarayana, C. \& Crosdale, P. J. (2002). Controls on methane sorption capacity of Indian coals. AAPG Bulletin, 86(2), 201-212.

[7] Tang, S. H., Cai, C., \& Zhu, B. C. (2008). Control effect of coal metamorphic degree on physical properties of coal reservoirs. Natural Gas Industry, 28(12), 30-33.

[8] Zhang, Q. L. (2008). Adsorption mechanism of different coal ranks under variable temperature and pressure conditions. Journal of China University of Mining and Technology, 18(3), 395-400. https://doi.org/10.1016/S1006-1266(08)60083-8

[9] Sakimoto, N., Shimada, S., Chai, Z. J., \& Li, H. Y. (2010). $\mathrm{CO}_{2}$ storage mechanism in coal and its effect on methane production in enhanced coalbed methane recovery. Journal of Energy and Power Engineering, 4(2), 1-7.

[10] Zhang, B. B., Dai, S. F., \& Luo, Y. B. (2010). Isothermal desorption characteristics of $\mathrm{CH}_{4} / \mathrm{CO}_{2}$ mixed gas for the Late Paleozoic coals from the Kailuan Coalfield of Hebei Province. Geological Review, 56(5), 753-760.

[11] Cai, Y. D., Liu, D. M., Pan, Z. M., Yao, Y. B., Li, J., \& Qiu, Y. (2012). Pore structure and its impact on CH4 adsorption capacity and flow capability of bituminous and subbituminous coals from Northeast China. Fuel, 103, 258268. https://doi.org/10.1016/j.fuel.2012.06.055

[12] Chen, R., Qin, Y., \& Wei, C. T. (2014). Differences in pore structures and adsorptivity between raw and two-stepsolvent-extracted vitrains. Natural Gas Geoscience, 25(7), 1103-1110. https://doi.org/10.11764/j.issn.1672-1926.2014.07.1103

[13] Day, S. \& Sakurovs, R. W. (2008). Supercritical gas sorption on moist coals. International Journal of Coal Geology, 74(1-4), 203-214.

https://doi.org/10.1016/j.coal.2008.01.003
[14] Kim, H. J., Shi, Y., \& He, J. W. (2011). Adsorption characteristics of $\mathrm{CO}_{2}$ and $\mathrm{CH}_{4}$ on dry and wet coal from subcritical to supercritical conditions. Chemical Engineering Journal, 171(1), 45-53. https://doi.org/10.1016/j.cej.2011.03.035

[15] Zhong, L. W. (2004). Adsorptive capacity of coals and its affecting factors. Earth Science - Journal of China University of Geosciences, 29(3), 327-332, 368.

[16] Langmuir, I. (1918). The adsorption of gases on plane surfaces of glass, mica and platinum. Journal of the American Oil Chemists Society, 40, 1361-1403. https://doi.org/10.1021/ja02242a004

[17] Brunauer, S., Emment, P. H., \& Teller, E. (1938). Adsorption of gases in multimolecular layers. Journal of the American Oil Chemists Society, 60, 309-319. https://doi.org/10.1021/ja01269a023

[18] Dubinin, M. M. (1975). Physical adsorption of gases and vapors in micropores. Progress in Surface Membrane Science, 9, 1-70. https://doi.org/10.1016/B978-0-12-571809-7.50006-1

[19] Fu, X. H., Qin, Y., \& Wei, C. T. (2007). Coalbed Methane Geology. China University of Mining and Technology Press, Xuzhou, 12-13.

[20] Dai, Y., Zhu, X., Chen, L. S., Liu, H., Zhang, T., \& Liu, S. J. (2015). A new multi-body dynamic model of a seafloor miner and its trafficability evaluation. International Journal of Simulation Modelling, 14, 732-743. https://doi.org/10.2507/IJSIMM14(4)C019

[21] Dai, Y., Liu, H., Zhang, T., Liu, S. J., \& Li, Y. (2016). Three dimensional coupled dynamic analysis of deep ocean mining system. Technical Gazette, 23(4), 1037-1045. https://doi.org/10.17559/TV-20150314135940

[22] Wang, X. R., Ren, G. L., \& Zhang, J. X. (2018). Numerical simulation and optimization analysis of thermal balance of heavy oil box-type substation louver arrangement. Mathematical Modelling of Engineering Problems, 5, 2126. https://doi.org/10.18280/mmep.050103

[23] Sun, G. Z., Zhang, R. L., \& Tian, K. Y. (2018). The dynamic evolution model and experimental study of gas permeability under multiple factors. International Journal of Heat and Technology, 36, 49-55. https://doi.org/10.18280/ijht.360107

[24] Suseela, Y. V. \& Reddy, J. S. K. (2017). A note on possible healing effects of conch shell frequencies. Neuro Quantology, 15,193-196. https://doi.org/10.14704/nq.2017.15.3.1033

[25] Nishino, J. (2001). Adsorption of water vapor and carbon dioxide at carboxylic functional groups on the surface of coal. Fuel, 80, 757-764. https://doi.org/10.1016/S0016-2361(00)00136-8 


\section{Contact information:}

\section{Run CHEN}

Corresponding author

1) Low Carbon Energy Institute (Key Laboratory of Coal-based $\mathrm{CO}_{2}$ Capture \& Geological Storage, Jiangsu Province), China University of Mining and

Technology, Xuzhou 221008, China

2) Henan Key Laboratory for Green and Efficient Mining \& Comprehensive

Utilization of Mineral Resources, Henan Polytechnic University, Jiaozuo 454000,

Henan, China

chenrun@cumt.edu.cn

\section{Youyang WANG}

School of Resource and Geosciences (Key Laboratory of Coalbed Methane

Resource \& Reservoir Formation History, Ministry of Education), China

University of Mining and Technology, Xuzhou 221008, China

wangfang5151@163.com

\section{Zhiyang WANG}

School of Resource and Geosciences (Key Laboratory of Coalbed Methane

Resource \& Reservoir Formation History, Ministry of Education), China

University of Mining and Technology, Xuzhou 221008, China

625773684@qq.com 